\title{
Emission control with route optimization in solid waste collection process: A case study
}

\author{
OMER APAYDIN* and M TALHA GONULLU \\ Yildiz Technical University, Environmental Engineering Department, 34349, \\ Yildiz, Istanbul, Turkey \\ e-mail: apaydin@yildiz.edu.tr
}

MS received 4 April 2006; revised 3 May 2007

\begin{abstract}
Solid waste collection processes are usually carried out by using trucks with diesel engine. In solid waste collection process, the trucks emit to environment different emissions from its exhausts. For this reason, in solid waste collection process, it is necessary that route optimization should be performed in order to decrease the emissions. This study was performed in Trabzon City with 39 districts, a shortest path model was used in order to optimize solid waste collection/hauling processes to minimize emission. Unless it performs route optimization in solid waste collection/hauling process, emissions increase due to empty miles negativeness. A software was used as an optimization tool. The software provided Geographical Information System (GIS) elements such as numerical pathways, demographic distribution data, container distribution data and solid waste production data. In addition, thematic container layer was having 777 points for the entire city. By using the software, the optimized route was compared with the present route. If the optimized route in solid waste collection system is used, route distance and route time will be decreased by $24.6 \%$ and $44.3 \%$ as mean of nine routes, respectively. By performing the stationary container collection process and route optimization, it is determined that $\mathrm{CO}_{2}, \mathrm{NOx}$, $\mathrm{HC}, \mathrm{CO}, \mathrm{PM}$ emissions will be reduced $831.4,12.8,1.2,0.4,0.7 \mathrm{~g}$ per route, respectively.
\end{abstract}

Keywords. Exhaust emission; route optimization; solid waste collection; GIS, Trabzon; Turkey.

\section{Introduction}

The solid waste management process can be commonly classified into generation, collection, storage, processing, transportation and disposal (Tchobanoglous et al 1993). In solid waste collection process, it is generally used trucks with diesel engine. In solid waste collection process, the trucks emit to environment several emissions from its exhausts. Emissions resulting from solid waste collection vehicles, of course, are proportional both to route time and

*For correspondence 
route distance. Conventional dispatching methods have generally focused on minimization. Decision support system approach has a focus on empty miles minimization (Taylor et al 2001). If empty miles minimization techniques are adopted in solid waste collection/hauling processes, vehicle emissions will be decreased. In a previous study (Tanskanen 2000), a model was proposed for reducing emissions such as $\mathrm{CO}_{2}, \mathrm{NOx}, \mathrm{VOCs}, \mathrm{SO}_{2}$ and obtained almost $30 \%$ success. Emissions from vehicles are based on travel distance and stop time of it. It has shown strong correlation of this increase in emissions with both fuel consumption and travel distance (Steven et al 2005).

In this study, a digital video camera was used to obtain data dealing with present collection facilities. The objective of the present study is to reduce the amount of the exhaust emissions from trucks used in solid waste collection process by means of optimized routes.

\subsection{The study area of Trabzon City}

1.1a Geography: Trabzon City (center) is located at the North Eastern part of Turkey. The city covers an area of $40 \mathrm{~km}^{2}$ as rounded. Trabzon is surrounded by Rize in the East, Giresun in the West, Gümüşhane in the South and the Black Sea in the North. Its length towards the East-West direction is $114 \mathrm{~km}$ and width $46 \mathrm{~km}$. The total area is $4685 \mathrm{~km}^{2}$. The area is mountainous and volcanic. The high mountains stretching from shore to the inner regions reach a height of $400-500 \mathrm{~m}$. The southern boundary of the city ends with hills of 2000-3000 m. These hills start from Coruh River in the East and end in OrduSamsun direction. Trabzon, with its hills and steep versans and streams that join the sea, has a rugged structure. The streams originate from the mountain series of the south of the city divided it into dense and deep valleys. Due to the mountainous structure of the area to the north, Trabzon is deprived of the wind coming from the south. Because of the masses of vapour above the sea can not reach beyond the mountains, it turns into rain (Keles 1995).

1.1b Population: The population of Trabzon City is $1,83,968$ according to the Census of 2000 (TURKSTAT 2002). But it is estimated that the present population is at 2,25,000 with about 60,000 households in the area. There are 39 districts in the city. Trabzon is a good transport hub from which to explore the Black Sea region.

1.1c Climate: Trabzon has typical of a Black Sea climate; with rain throughout the year and temperatures reaching up to around $27^{\circ} \mathrm{C}$ in the summer. Winters are cool and damp, and the lowest temperature is around $5^{\circ} \mathrm{C}$ in January. The water temperature fluctuates between 10 and $20^{\circ} \mathrm{C}$ throughout the shoreline (Keleş 1995).

1.1d History: The city was first founded by Colonists from Sinope and Miletus during the 8th century BC, originally called Trapezus (derived from the ancient Greek word for table) and situated above the harbour. It prospered under the Romans and Byzantines, mainly in the shipping trade, and as a branch of the Silk Road. When the Fourth Crusaders seized Constantinople in 1204, the imperial family from Comnenus established an empire along the Black Sea Coast and Alexius set up the Empire of Trebizond. This was a golden era for the city, and the 13th and 14th centuries saw the reign of Alexius II who created great wealth, trade and culture, making Trebizond something of an artistic icon to rival the great Italian Renaissance. His reign ended after a destructive civil war in 1341, and over a century later (1461) Mehmet, the Conqueror brought the city under Ottoman rule and revived the port as a trading centre. 


\subsection{Solid waste management in Trabzon City}

Trabzon Municipality serves with about 2,800 garbage collecting containers in different sizes $(150,300$, and $400 \mathrm{~L})$ in the residential area. Domestic wastes from households are dropped by inhabitants into these containers. Containers are unloaded at least twice a week by about 20 trucks (total capacity of trucks is $154 \mathrm{~m}^{3}$ ). The total length of road network is $416 \mathrm{~km}$ and vehicles pass through its about $60 \%$ each day. On the other hand, waste collection through some busy streets such as Maras Caddesi is 7-8 times a day. Collection facility is subjected for 6 days in a week. Due to the reasons such as not being smooth topography and small city size, there is no transfer station in the city yet. Collected garbage is dumped at sea side of Black Sea by blending with soil in a ratio of about $50 \%$. The dumping area in $2 \mathrm{Ha}$ and has been prepared as surrounded by breakwater walls on the sea. This kind of dumping creates considerable sea pollution (Apaydin 2004). Annual income of inhabitants living in Trabzon City are US\$ 6100 (min: 1,800, mean: 6,100, max: 42,000) (Apaydin et al 2002). It has been observed that BMC Fatih 180 model vehicles with CUMMINS Engine (Euro 1) having the high performance and satisfactory fuel consumption are in common use for MSW collection/hauling processes in Trabzon City.

\section{Materials and methods}

In this study, a video camera marked Sony DCR-TRV145E was used in order to analyse solid waste collection/hauling process as recorded. Emissions from existing solid waste collection/hauling were estimated based on data obtained, records analysed and the other GIS database. Projection of digitizing map using this study adjusted Turkish Coordinate System (GK 3 Degree $k=1-$ ED50 and Category Members: GK Central Meridian 39 (ED50)). The map contains several layers and 39 quarter districts. A shortest path model was used in order to optimize solid waste collection/hauling processes, as minimum distance aimed. For that purpose, Route View Pro ${ }^{\mathrm{TM}}$ software was used as an optimization tool. A shortest path model can be obtained with the software. In the shortest path problem (dynamic shortest path problem), travel time and travel cost on an edge are no longer assumed to be time-independent, but are expressed as a function of when travel along the edge starts. This implies that the cheapest path between two locations, and its duration and cost, are also not constant, but may vary with when travel starts. Moreover, if the goal is to find the cheapest path, where the notion of cheap does not coincide with the notion of fast, then there may exist a collection of pareto optimal paths. These paths exhibit the possible trade-offs, cheap and fast paths.

The software was also operated with GIS elements such as numerical pathways, demographic data, container distribution data and solid waste production data. RouteView Pro ${ }^{\mathrm{TM}}$ is a software, which provides comprehensive routing and catchment area analysis.

Different analyses can be done with the software. The travel distances and travel times for sales/maintenance field force can be calculated. The route for pick-ups and deliveries to customers can be optimized. The potential of a proposed site based on a cross-section of population within specified travel times or travel distances from the site can be determined. Catchment areas for a sales campaign can be analysed. Customers with an accurate estimate of arrival time can be provided. Turn restrictions and one-way/impassable information can be added. Road segments can be added and deleted. Road edits to a network can be imported and exported. Different speeds for different times of the day can be assigned. Where is the nearest? functionality can be carried out. Journey directions for any route can be obtained. 
Origin-destination data to run a frequency analysis can be used and restrictions can be added based on height, width, weight, etc.

A topologically correct road network is necessary to use the software. In creating a network from an existing database of streets, it can get route descriptions and temporarily close or slow down the speed limits for roads. RouteFinder is able to handle large networks and identify topological problems in road networks.

\subsection{Determination of container and vehicle capacities}

The number of buildings per road distance was determined using the present map of Trabzon City having several layers such as road distance, building numbers per road distance, household numbers per building. The number of household was determined using cadastral survey and the map of Trabzon city. The amount of solid waste per person (M) was determined based on route observations and solid waste collection database.

Container number $\left(n_{K}\right)$ is computed as

$$
n_{K}=\frac{p}{P_{K}}
$$

where $p$ is population living in study area, $P_{K}$ is population for a container. $P_{K}$ is computed as

$$
P_{K}=\frac{V_{K}}{V_{R P}}
$$

$V_{K}$ is volume of a container $\left(\mathrm{m}^{3}\right), V_{R P}$ is volume of MSW per person $\left(\mathrm{m}^{3}\right) ; . V_{R P}$ is computed as

$$
V_{R P}=\frac{V_{R}}{P_{R}} \text { or } V_{R P}=\frac{M}{W_{p}}
$$

$V_{R}$ is volume of MSW per residence $\left(\mathrm{m}^{3}\right)\left(V_{R} \cong 4 \cdot 1 V_{R P}\right), P_{R}$ is number of person per a residence, $\mathrm{M}$ is MSW amount per person a day ( $\mathrm{kg} /$ person.day), $W_{p}$ is unit volume per $\mathrm{kg}$ of MSW in a container. Required MSW container number for a vehicle is presented as

$$
n_{K}^{\prime}=\frac{V_{v}}{V_{K}} \alpha
$$

where $V_{v}$ is volume of a vehicle $\left(\mathrm{m}^{3}\right), n_{K}^{\prime}$ is container number for a vehicle, $\alpha$ is vehicle compaction factor.

\subsection{Fuel-based emission factors}

The engine of trucks using for solid waste collection in the study area are either Euro 1 or older. A study performed by Barnaud et al (2000) carried out CUMMINS Engine with 6 cylinders and emissions measured are presented at table 1.

In this study, exhaust emissions were estimated for both present routes and optimized routes by using the data existed in table 1 . The results obtained in this study are given in the next sections. 
Table 1. CUMMINS Engine with 6 cylinders (Euro 1) exhausts emissions based on travel distance.

\begin{tabular}{ll}
\hline Parameters & \multicolumn{1}{c}{ Values } \\
\hline Fuel consumption & $33.21 \mathrm{Liter} / 100 \mathrm{~km}$ \\
$\mathrm{CO}_{2}$ & $893.5 \mathrm{~g} / \mathrm{km}$ \\
$\mathrm{NOx}$ & $13.81 \mathrm{~g} / \mathrm{km}$ \\
$\mathrm{HC}$ & $1.34 \mathrm{~g} / \mathrm{km}$ \\
$\mathrm{HC}+\mathrm{NOx}$ & $15.15 \mathrm{~g} / \mathrm{km}$ \\
$\mathrm{CO}$ & $0.43 \mathrm{~g} / \mathrm{km}$ \\
$\mathrm{PM}$ & $0.767 \mathrm{~g} / \mathrm{km}$ \\
Smoke capacity & $1.47 \mathrm{~m}^{-1}$ \\
\hline
\end{tabular}

\section{Results and discussion}

The digitized map performed in this study is presented in figure 1. Data were collected for 9 different routes over 13 collection days on November 2004. Using a digital camera, visual records were made in the collection vehicle cabinet to observe route variations. Distances proceeded through the route were cross checked between digitized map and vehicle tachometer.

Figure 2 presents route and optimized routes compares with each other. When optimized route performed in solid waste collection system the distance of optimized route decreases as $44.3 \%$ of the mean of the nine optimized routes.

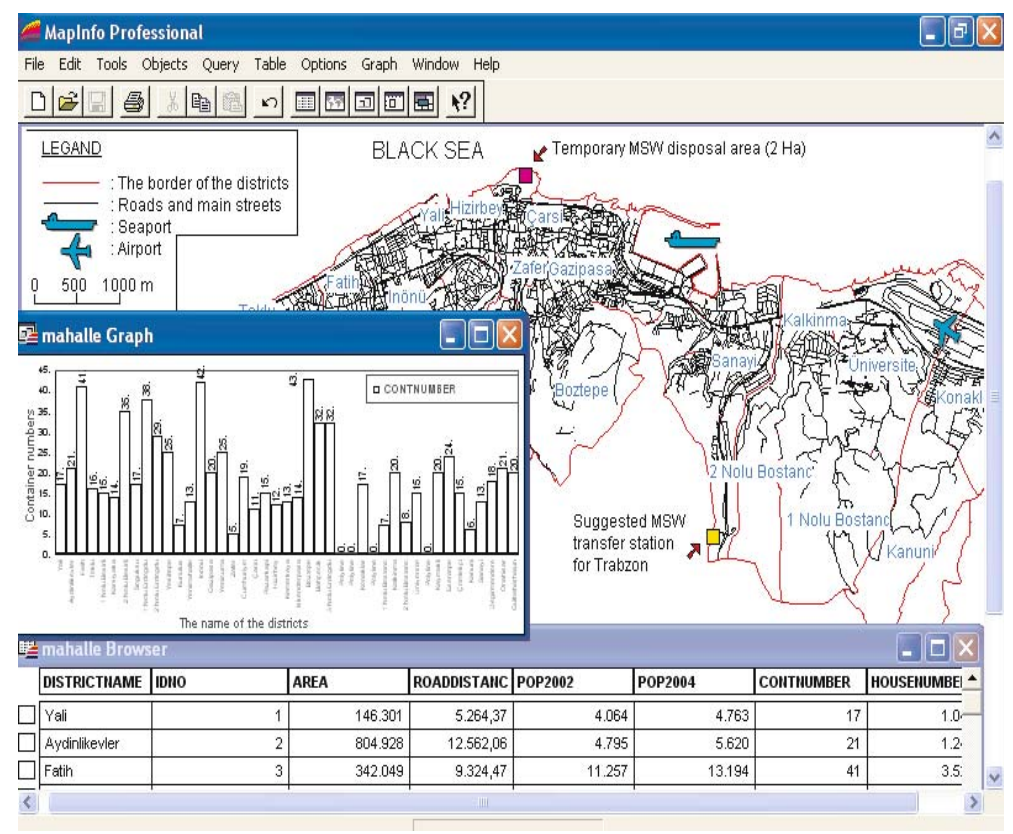

Figure 1. Digitized map of Trabzon City and GIS data. 


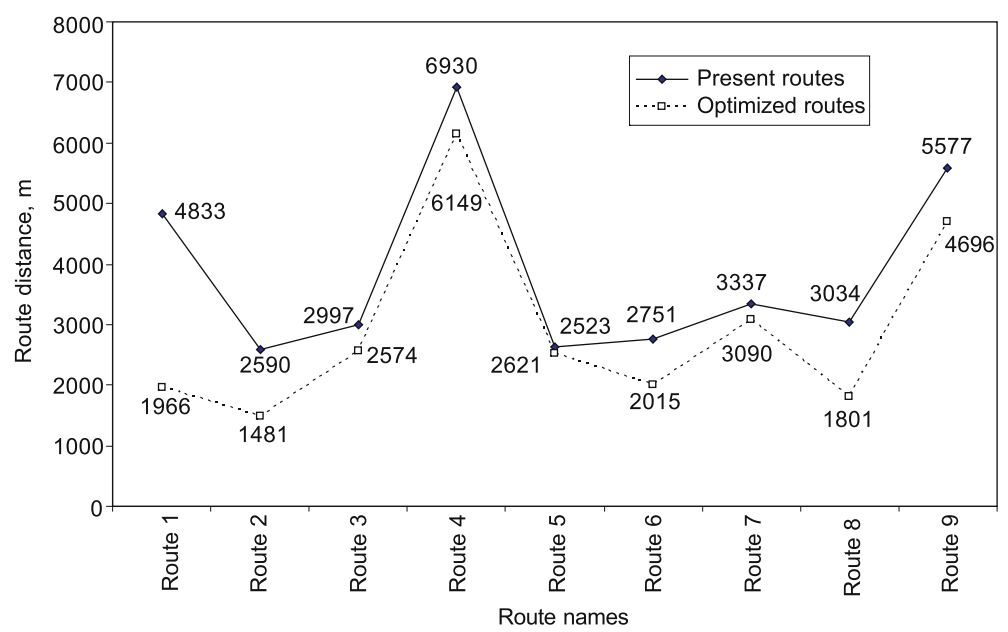

Figure 2. The change of route distance between present and optimized routes.

According to figure 3, when optimized route performed in solid waste collection system the travel time of the optimized routes decreases as $24.6 \%$ of the mean of the optimized routes.

In this study, BMC Fatih 180 model trucks were used to perform the solid waste collection process. Vehicle mean velocities for present and optimized routes are presented in figure 4.

According to figure 4, for 139 different measurements, the mean velocities of present and optimized routes are $9.69 \mathrm{~km} / \mathrm{h}$ and $9.87 \cdot \mathrm{km} / \mathrm{h}$, respectively. As a result of that, it can be said that the vehicle mean velocity for optimized route is observed as faster about $2 \%$ than present route. Furthermore, another observation from the figures is that the vehicle velocities have been increased and densed around mean vehicle velocity incase of the optimized routes.

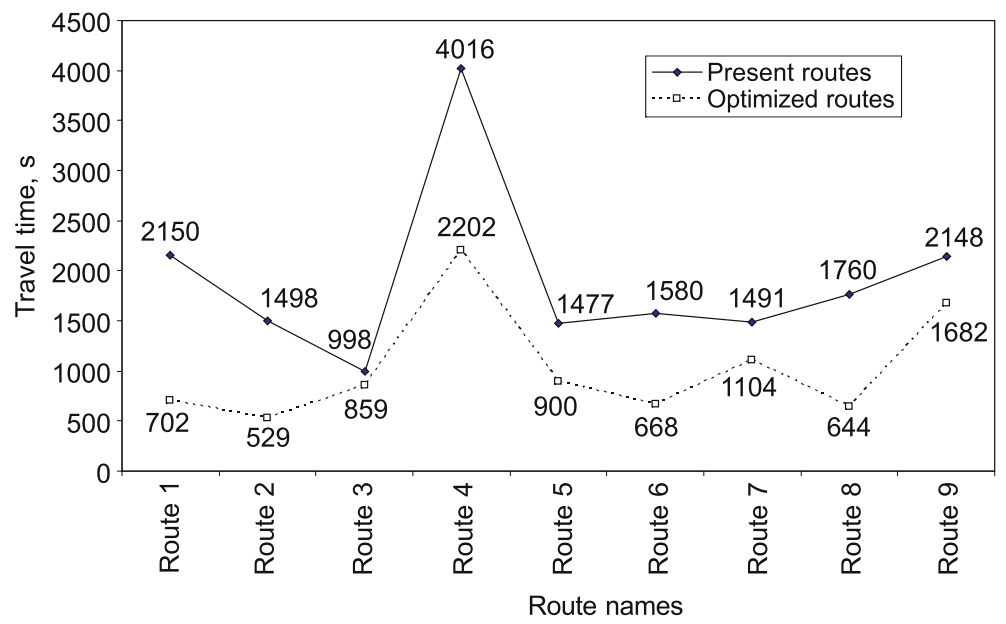

Figure 3. The change of travel time between present and optimized routes. 


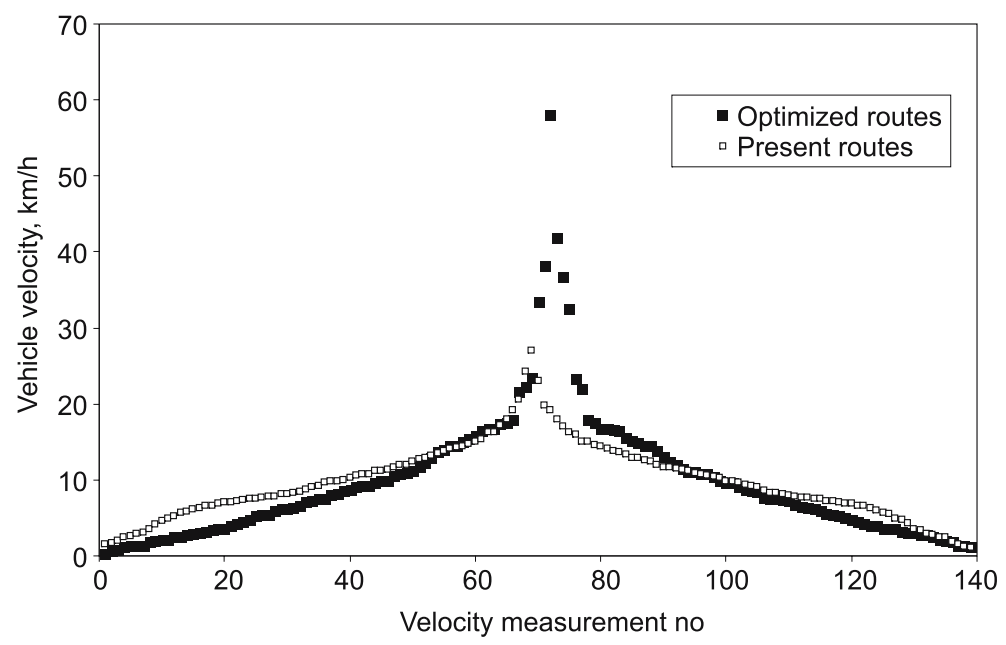

Figure 4. Vehicle velocities on the optimized routes.

Correlation between vehicle velocity data obtained with monitoring study by digital video camera and travel distance by collection vehicle on the present routes are given in figure 5. By means of 405 observations, vehicle mean velocity in the area is found about $11.39 \mathrm{~km} / \mathrm{h}$.

By using emission factors given in table 1, emissions originating from solid waste collecting vehicle are presented in figures 6-11.

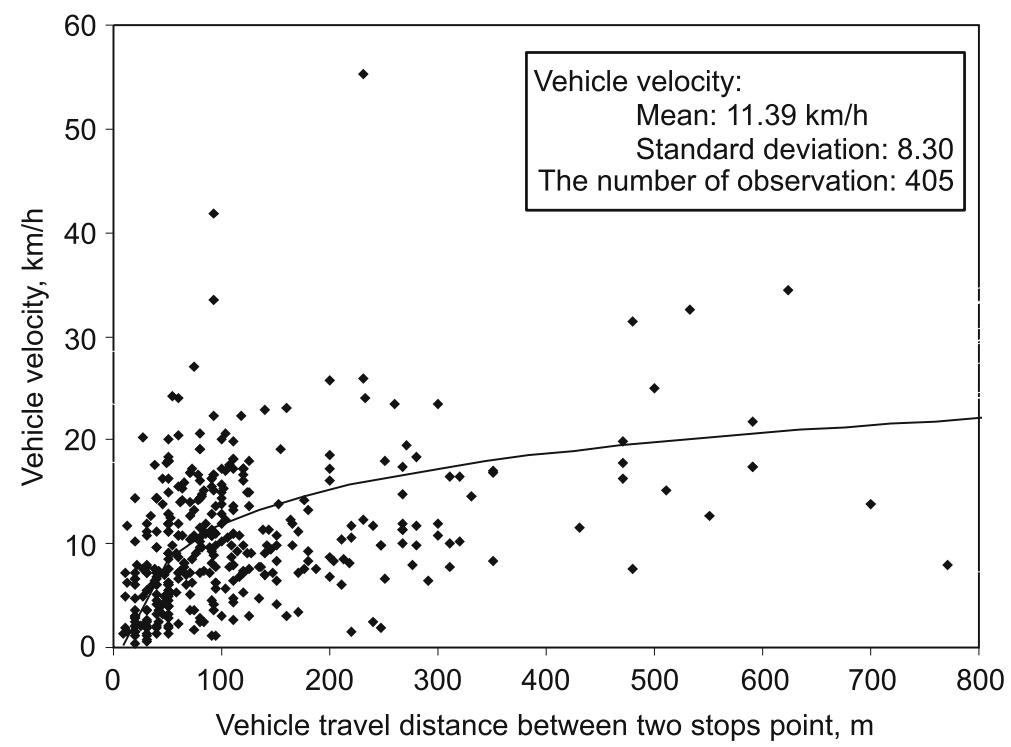

Figure 5. Correlation between vehicle velocities and travel distance on the present routes. 


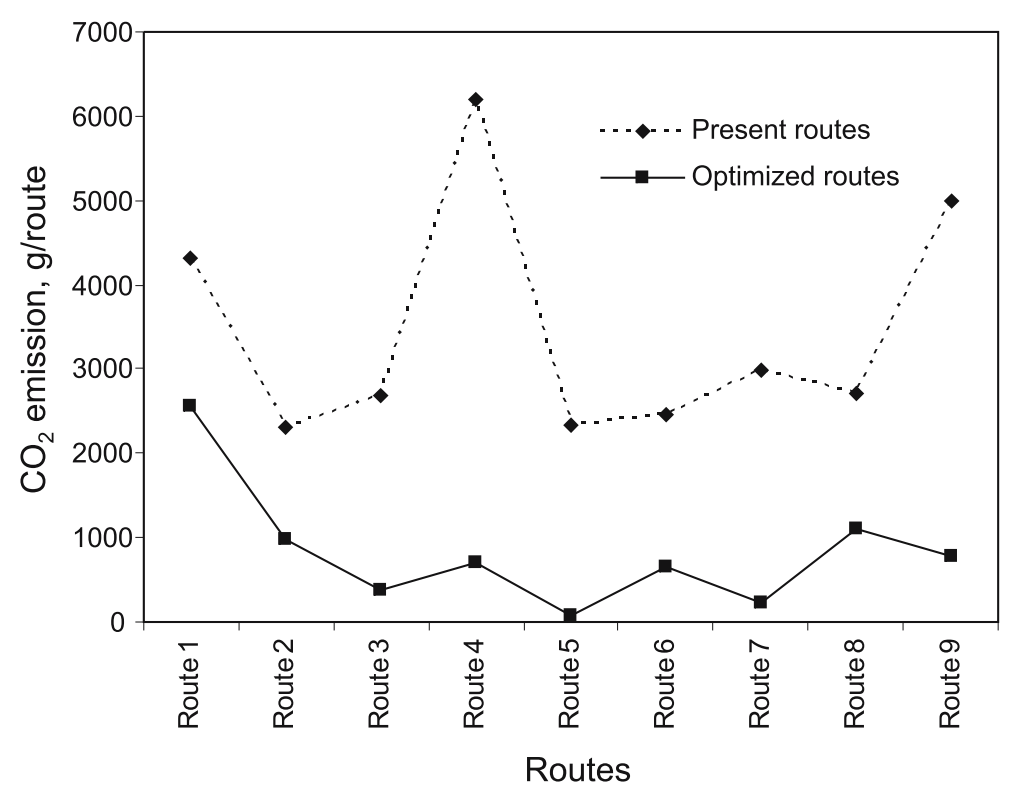

Figure 6. $\mathrm{CO}_{2}$-emissions estimated for present and optimized routes.

According to figure $6, \mathrm{CO}_{2}$ emissions are changed between $2314 \cdot 1 \mathrm{~g} /$ route and $6191.9 \mathrm{~g} /$ route at present routes whereas it is changed between $87.5 \mathrm{~g} /$ route and $2561.6 \mathrm{~g} /$ route at optimized routes.

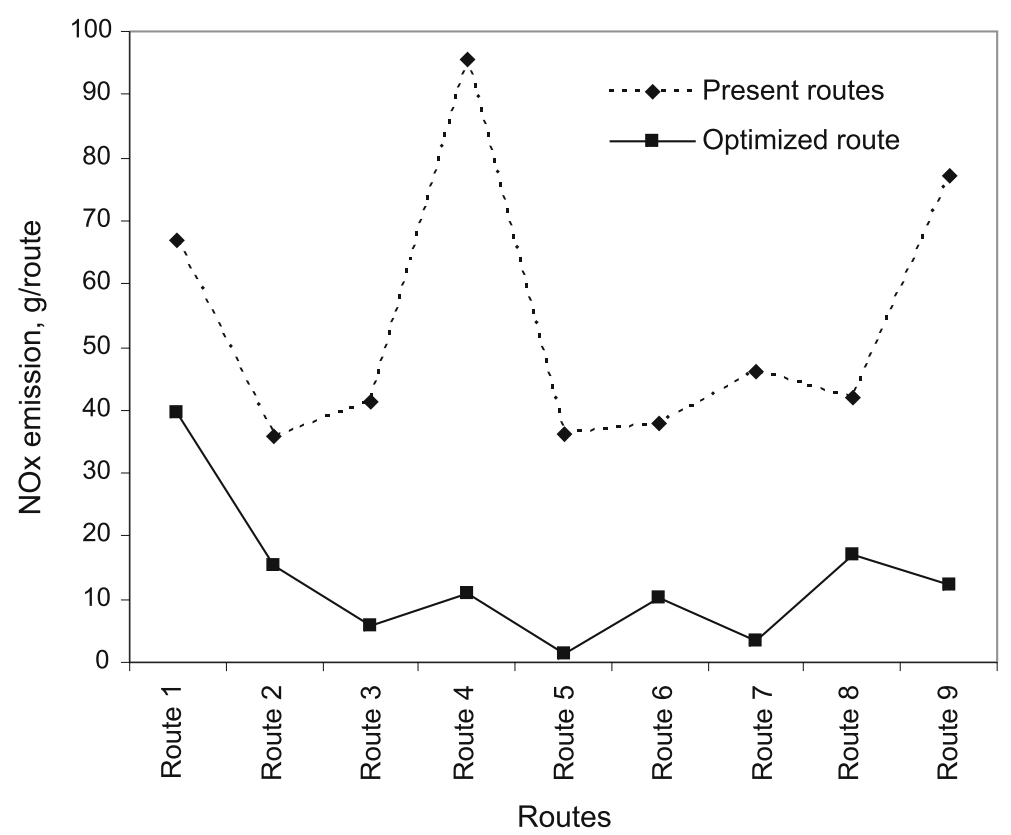

Figure 7. NOx-emissions estimated for present and optimized routes. 


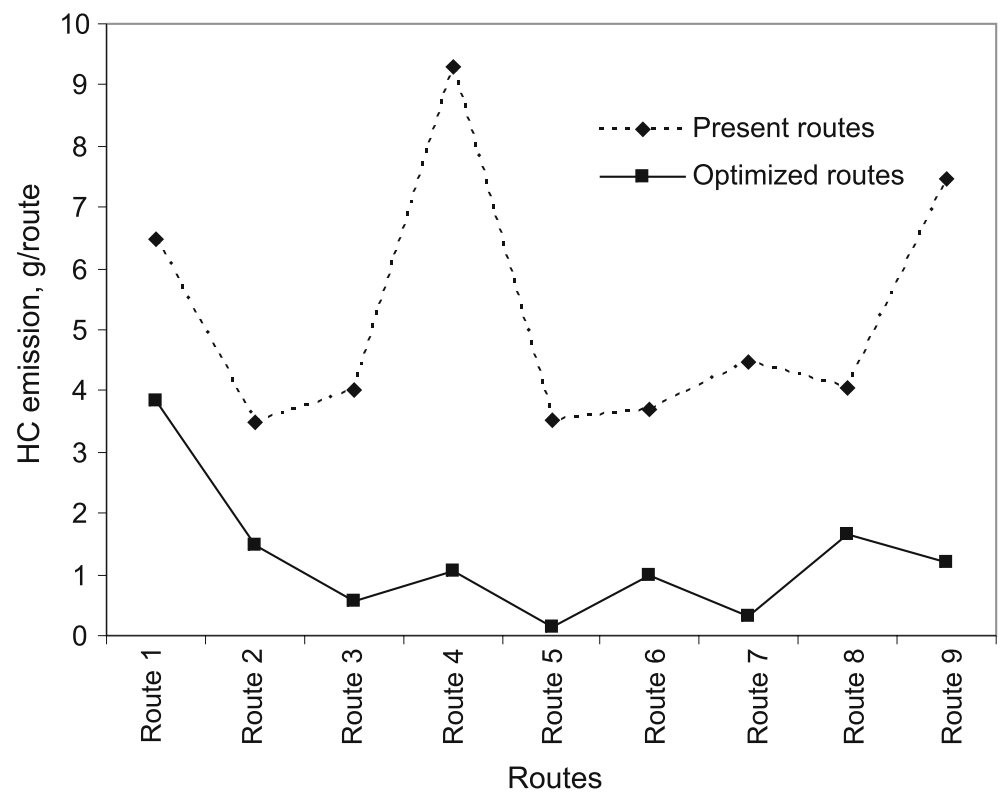

Figure 8. HC-emissions estimated for present and optimized routes.

According to figure 7, NOx emissions are changed between $35.7 \mathrm{~g} /$ route and $95.7 \mathrm{~g} /$ route at present routes whereas it is changed between $1.3 \mathrm{~g} /$ route and $39.5 \mathrm{~g} /$ route at optimized routes.

According to figure $8, \mathrm{HC}$ emissions are changed between $3.4 \mathrm{~g} /$ route and $9.2 \mathrm{~g} /$ route at present routes whereas it is changed between $0.1 \mathrm{~g} /$ route and $3.8 \mathrm{~g} /$ route at optimized routes.

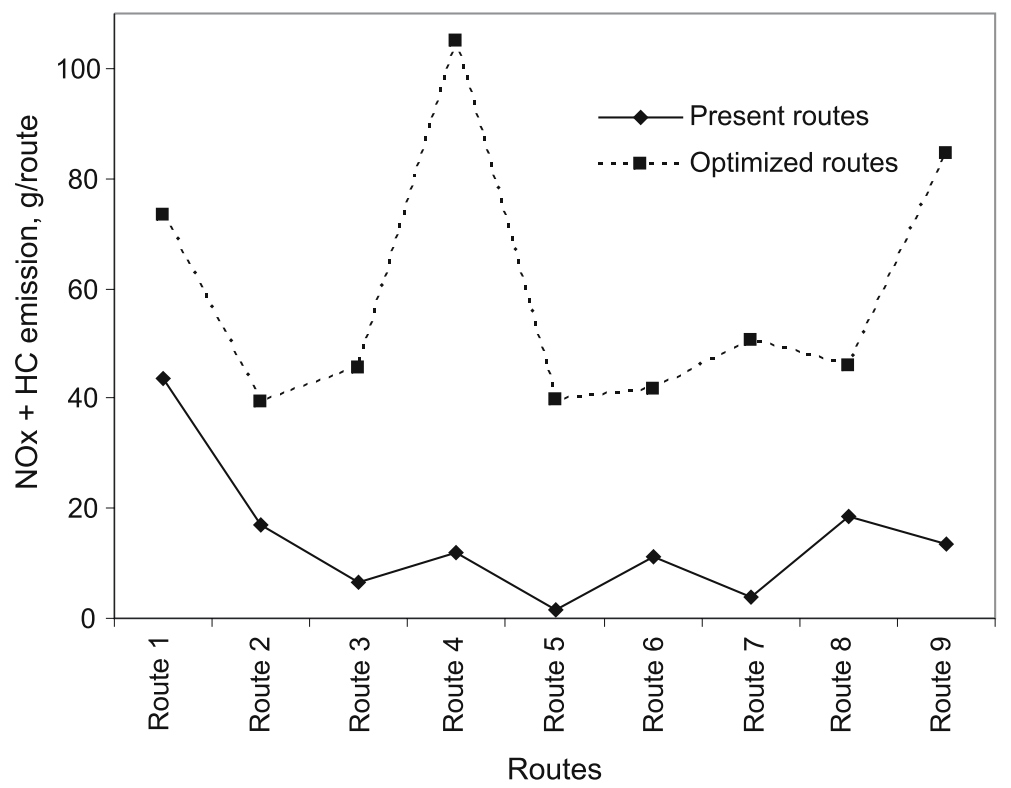

Figure 9. NOx + HC-emissions estimated for present and optimized routes. 


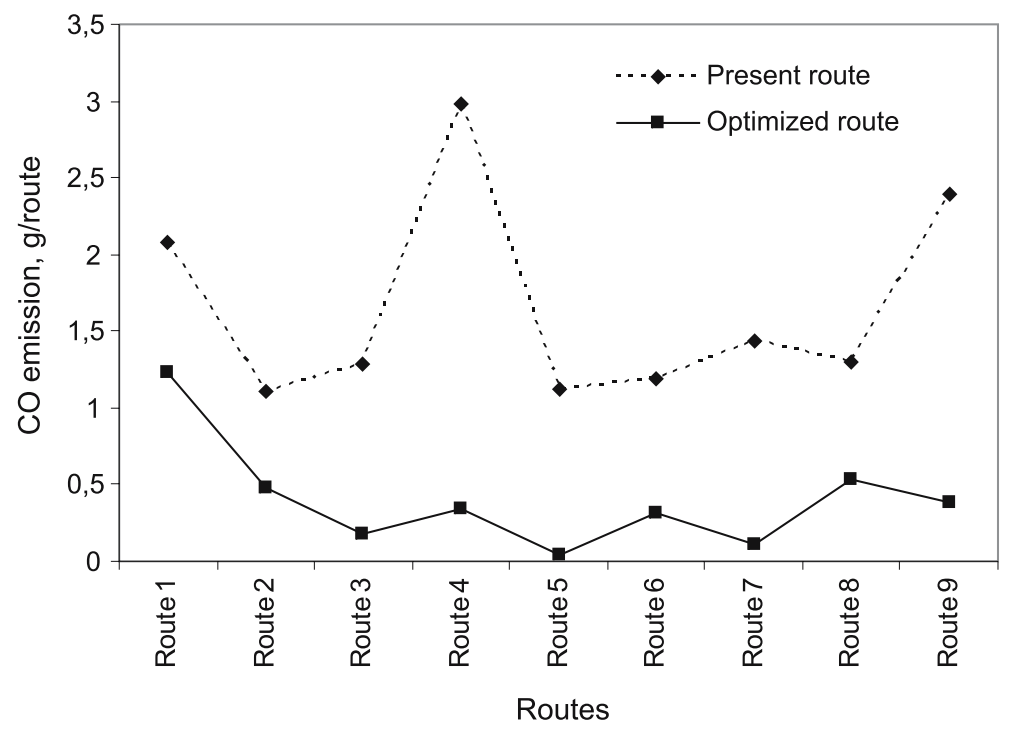

Figure 10. CO-emissions estimated for present and optimized routes.

In figure $9 \mathrm{NOx}+\mathrm{HC}$ emissions are changed between $39.2 \mathrm{~g} /$ route and $104.9 \mathrm{~g} /$ route at present routes whereas it is changed between $1.4 \mathrm{~g} /$ route and $43.4 \mathrm{~g} /$ route at optimized routes.

According to figure 10, CO emissions are changed between $1.1 \mathrm{~g} /$ route and $2.9 \mathrm{~g} /$ route at present routes whereas it is changed between $0.1 \mathrm{~g} /$ route and $1.2 \mathrm{~g} /$ route at optimized routes.

As shown in figure 11, PM emissions are changed between $1.9 \mathrm{~g} /$ route and $5.3 \mathrm{~g} /$ route at present routes whereas it is changed between $0 \cdot 1 \mathrm{~g} /$ route and $2 \cdot 1 \mathrm{~g} /$ route at optimized routes.

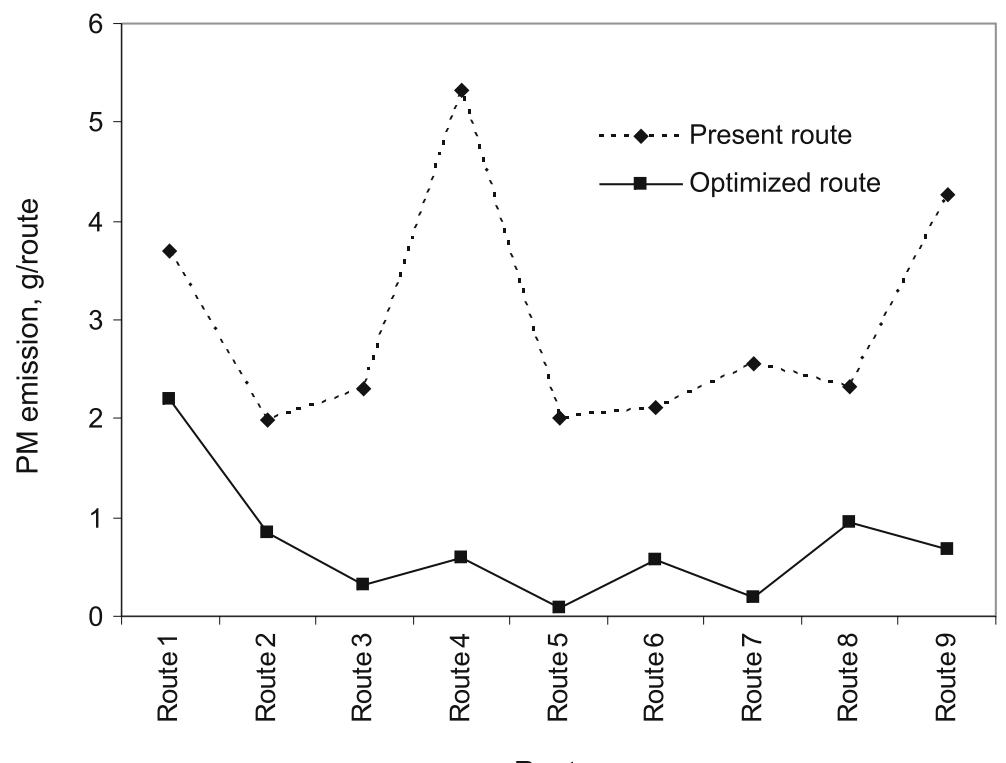

Routes

Figure 11. PM-emissions estimated present and optimized routes. 
According to the results obtained from the this study, if solid waste collection process with stationary container and route optimization are applied syncronously, $\mathrm{CO}_{2}, \mathrm{NOx}, \mathrm{HC}, \mathrm{CO}$, PM emissions originated from wehicle exhaust can be reduced by $831.4,12 \cdot 8,1 \cdot 2,0.4,0.7 \mathrm{~g}$ per route, respectively.

\section{Conclusions}

In the previous studies done in the area about collection costs (Apaydin \& Gonullu 2006) and route optimization (Apaydin et al 2004; Apaydin 2005), the necessity of the route optimization for solid waste collection routes was also emphasized. In this study, solid waste collection data (mostly from review of digital camera records and field observations) of Trabzon City were transferred into GIS in order to provide high quality data for solid waste management. It was a complex system to transfer all the data related to solid waste of Trabzon City and required large amounts of available data. Thus, data contained in various databases and solid waste collection parameters were transferred into GIS database to create Trabzon road network for the management and monitoring of solid waste data. The solid waste network enables its users to constitute a database and to realize statistical and query analysis on it. Another gain of the optimized route is vehicle is being less time in traffic. Reduction of exhaust gas emissions is a normal result of this type optimization effort. Emission factors changing with truck speeds for truck types in use will be targeted in the future research work.

\section{Acknowledgements}

The authors thank the Basarsoft for their assistance in the software used in this study. This research has been supported by Yildiz Technical University Scientific Projects Coordination Department (Project Number: 24/05/02.02).

\section{References}

Apaydin O, Kalender A, Gonullu M T 2002 Assessment of sociological aspect of separate household solid waste collection in Trabzon (Turkey), in: ISWA 2002 World Environmental Congress and Exhibition, July 8-12, 2002, Istanbul, Turkey, 5: 2955-2960

Apaydin O 2004 Geographical Information System (GIS) supported optimization of solid waste management alternatives in Trabzon City, Ph.D. Thesis, YTU Science Institute, Environmental Engineering, Istanbul, Turkey

Apaydin O 2005 A GIS supported optimization application of solid waste collection system in Trabzon City, Ekoloji 54: 1-6

Apaydin O, Arslankaya E, Avsar Y, Gonullu M T 2004 GIS supported optimization of solid waste collection in Trabzon, Sigma 2004/4, 249-254

Apaydin O, Gonullu M T 2006 Route optimization for solid waste collection: Trabzon (Turkey) case study, Global NEST Journal 9: 6-11

Barnaud F, Schmezle P, Schulz P, June 2000 AQUAZOLET: An original emulsified water-diesel fuel for heavy-duty applications, diesel and gasoline performance and additives, (USA: Society of Automative Engineers, Inc.) 95-99

Keles R 1995 The Management of the coastal zone of Trabzon City, Trabzon, Turkey (Trabzon ili kiyi yonetimi) Ankara (Turkey): Oztug Matbaasi Press 1-210 
Schifter I, Diaz L, Mugica V, Lopez-Salinas E 2005 Fuel-based motor vehicle emissions inventory for the metropolitan area of Mexico City, Atmospheric Environment 34: 931-940

Steven H Cadle, Timothy C Belian, Kevin N Black, Fred Minassian, Mani N, Eugene J Tierney, Douglas R Lawson 2005 Real-world vehicle emissions: A summary of the 14th Coordinating Research Council on-Road Vehicle Emissions Workshop, J. Air and Waste Management Assocn. 55: $130-146$

Tanskanen J H 2000 Strategic planning of municipal solid waste management, Resources, Conservation and Recycling, 30: 111-113

Taylor GD, Whicker G L, Usher J S 2001 Multi-zone dispatching in truckload trucking, Transportation research, (Part E, Logistics and Transpartation Review) 37: 375-390

Tchobanoglous G, Theisen H Vigil S A 1993 Integrated solid waste management: Engineering principles and management issues. (New York: USA, McGraw-Hill)

TURKSTAT 2002, Population Censuses, year 2000: city 61-Trabzon, ISBN 975-19-3065 